\title{
INVESTIGATING MECHANISMS TO INCREASE STUDENT ENGAGEMENT IN HIGHER EDUCATION LEARNING ENVIRONMENTS: TESTING EMERGING AND IMMERSIVE TECHNOLOGIES TO MEET TEACHING NEEDS
}

\author{
Michael Detyna ${ }^{1 *}$, \\ Ivan Stojšić \\ Eleanor J. Dommett ${ }^{3}$ \\ ${ }^{1}$ Centre for Technology Enhanced Learning, \\ King's College London, \\ London, UK \\ 2University of Novi Sad, Faculty of Sciences, \\ Novi Sad, Serbia \\ ${ }^{3}$ Department of Psychology, \\ Addison House Guy's Campus, \\ King's College London, UK
}

\begin{abstract}
:
Based on the current research evidence on the effectiveness of lectures, it is possible to conclude that lectures can be of value, provided they are structured as interactive events and not periods consisting solely of presentations by the lecturer. With such a range of educational technologies available (including augmented and virtual reality), it is important to ensure that the appropriate digital tools are adopted. One of the key factors in this decision must be the views of staff and students. In this paper, a part of workshop-based research (involving teaching demonstration, direct interaction and feedback) about immersive technologies with staff and students $(\mathrm{N}=33)$ from King's College London was presented. The findings have shown that participants had a wide variety of views about the use of augmented and virtual reality, as well as different needs regarding technological solutions in learning environments. Novelty of this research is demonstrated providing an overview of the landscape of pedagogical possibilities of immersive technologies using simplified didactic process maps.
\end{abstract}

Keywords:

higher education learning environments, students' engagement, technologyenhanced learning, augmented reality, virtual reality.

\section{INTRODUCTION}

Conventional lectures are the dominant form of instruction in most universities. Yet there are several issues with them as a mechanism for educational delivery. Kelly et al. [1] observed student engagement across three instructional methods (lecture, problem-based and team learning) and found engagement to be the lowest in the lecture. The common oneto-many transmissive nature of lectures can create a passive learning experience and does not always foster sufficient engagement. Further, large attendance lectures are not always successful at providing interaction opportunities. Also, as Schmidt et al. [2] argued, lectures often "do not promote critical thinking; student attendance tends to be low and so is cognitive engagement" (p. 12), and many students find lectures to be both lacking in interest and only partially effective at aiding learning.
Correspondence:

Michael Detyna

e-mail:

michael.detyna@kcl.ac.uk 
Additionally, Mann and Robinson [3] pointed out that boredom in lectures is a significant factor in diminished academic achievement. Indeed, this has led some such as DiPiro [4] to question why we have lectures at all. However, while there are issues with conventional in-person lectures, their use is widespread, and they can be a positive learning experience for many students [5].

Saito and Smith [6] identified some factors relating to engagement, which emphasised the environment and psychology of the learner. Lectures incorporating active learning methods have a strong empirical basis for increasing student engagement and examination grades as compared to traditional lectures. For example, the research conducted by Freeman et al. [7] found that undergraduate science, technology, engineering and mathematics (STEM) students' performance on examinations and concept inventories increased by 0.47 standard deviations under active learning, and that students in traditional classes were 1.5 times more likely to fail compare to students in classes with active learning sections.

Given the importance of engagement this has been the focus of several reviews. These reviews suggest a need to explore what engagement is from the students' perspective i.e., get their views. They also suggest that it is the responsibility of universities to engage students by fostering a suitable environment and one way to do this is by using innovative digital technologies. A comprehensive literature review [8] covered directions for future research, and two key points it raises are: "exploration of the concept of 'student engagement' from the student perspective" and "a locally grounded but internationally validated conceptualisation of student engagement" (p. 50). Those looking at a prospective policy framework for supporting universities, should see student engagement as a metric to raise attainment. Therefore, finding appropriate digital tools and solutions to support teaching and learning should be on the priority list.

\subsection{DIGITAL TOOLS AND IMMERSIVE TECHNOLOGIES}

A range of digital tools and technologies exist to increase learner engagement in $\mathrm{HE}$, such as: audience response systems, backchannel communication, screen mirroring, virtual reality (VR ) and augmented reality (AR) [9]-[13]. Alongside these tools, there are also different pedagogical approaches that can be used.

Immersive technologies (such as AR and VR) are emerging as tools that both HE staff and students express a great deal of interest in, and show promising results regarding engagement in different academic disciplines [9], [13]-[17]. Scavarelli et al. [18] have conducted a literature review regarding the educational use of VR and AR within social learning spaces (e.g., classrooms and museums) and provided an overview of pedagogical foundations that support VR/AR learning, as well as explored several examples. Akçayır and Akçayır [14], in their systematic review, emphasized advantages and challenges associated with the educational use of AR, and Garzón and Acevedo [15] identified that AR has a medium size effect on the learning gains $(\mathrm{d}=.68)$ based on a meta-analysis of 64 quantitative research papers. Radianti et al. [17] conducted a systematic review of immersive VR for HE purposes and identified three key points (the domain structure regarding the learning contents, the VR design elements, and the foundational learning theories), as well as 18 application domains.

\section{PURPOSE AND RESEARCH QUESTIONS}

Even before the COVID-19 pandemic, the majority of universities worldwide were in some phase of digital transformation [19], and the King's Strategic Vision 2029 sets out a number of important points including to utilize modern technology to enhance teaching and research excellence.

This project was initiated to examine various emerging technologies and consider which ones could be useful in learning environments, as we need student perspectives on what is engaging but also recognise that staff must work with technology and views are often different [5]. Therefore, the key factor of this workshop-based research was that both staff and students had a physical (hands-on) experience and could give honest feedback about each technology and the practicalities of its use. In this research we aimed to address the following research questions (RQ) about immersive technologies:

- RQ1 What technological solutions do participants think they need in the learning environments to improve teaching and increase students' engagement, and what requests can be met with tested digital tools and immersive technologies?

- RQ2 How do academics and students evaluate potential benefits and challenges of the educational use of immersive technologies?

- RQ3 What would simplified didactic process maps of possible pedagogical aims look like? 


\section{MATERIALS AND METHOD}

Ethical approval was obtained from the relevant Institutional Ethics Committee (Ref MR/16/17-744) in advance. The methods used in this research are described in detail in Detyna and Dommett [20] but briefly, teachers and students were recruited through advertising (posters, emails and via institutional VLE) at the King's College London and were not compensated for their time participating in demonstration sessions, hands-on activities and focus group discussion. All participants $(\mathrm{N}=33)$ were provided with study information and written consent. In total 23 staff members and 10 students took part in this research.

Participants attended sessions which were divided into three parts. The first part of the session was a teaching demonstration using the topic of how elements are formed in the stars. The example was chosen because it can be delivered with a clear narrative arc and engage learners with the use of different technologies within the discrete period available. Immediately following the demonstration, participants were given around 60 minutes to interact with the different technologies demonstrated.

Presented technologies and tools were grouped, and the results regarding other tested digital tools (besides VR and AR) were covered in a publication by Detyna and Dommett [20]. The final part of the session aimed to gain feedback from participants about the individual tools and technologies. The research was continued with an in-depth focus group discussion, following Kahn's [21] conceptualisation of engagement which emphasized social interaction and group dynamics about the potential value of the technologies. Discussion centred on the following questions: (a) "What learning goals could this tool help you achieve?", (b) "How could you use this in a teaching environment?" and (c) "What are the pros and cons of this technology?". Responses were audio recorded.

\subsection{DATA ANALYSIS}

The audio recordings of focus groups were transcribed generating in total circa 15,000 words of response and then thematically analysed using the process outlined by Braun and Clarke [22]. Additionally, simplified didactic process maps were created using a visual approach which builds on the work of Döbeli Honegger and Notari [23].

\section{RESULTS}

\subsection{RQ1 IMPROVING TEACHING AND ENGAGEMENT}

A number of staff requests came up in response to prompts about technologies to best support their students. These have been codified by discourse.

Table 1 shows the major "blue skies thinking" themes discussed by academics and students based on their prior experience. The results indicated that the staff and students highly prioritized the need for improving students' engagement during the lectures with technological solutions. AR/VR technology can be potentially useful for improving the visual presentation of teaching content and providing interactive solutions for improving student engagement.

\begin{tabular}{|c|c|c|}
\hline Themes & Example quote & $\mathbf{n}$ \\
\hline $\begin{array}{c}\text { Student } \\
\text { communication }\end{array}$ & $\begin{array}{l}\text { "For teachers and } \\
\text { students to have a way of } \\
\text { communicating that is } \\
\text { anonymised, and that is } \\
\text { easy to do." } \\
\text { "Mobile phone exchange } \\
\text { between staff and students } \\
\text { like text messaging." }\end{array}$ & 6 \\
\hline $\begin{array}{l}\text { Better visual } \\
\text { technology }\end{array}$ & $\begin{array}{c}\text { "Visualisers in every } \\
\text { room." }\end{array}$ & 6 \\
\hline $\begin{array}{l}\text { Improved lecture } \\
\text { capture }\end{array}$ & $\begin{array}{l}\text { "Lecture capture more } \\
\text { easily editable." } \\
\text { "Adding text captions to } \\
\text { lecture capture." }\end{array}$ & 5 \\
\hline $\begin{array}{c}\text { Student } \\
\text { collaboration }\end{array}$ & $\begin{array}{l}\text { "Anything that allows } \\
\text { students to collaborate } \\
\text { and share thoughts about } \\
\text { content in real time." }\end{array}$ & 4 \\
\hline $\begin{array}{c}\text { Physical } \\
\text { infrastructure (tech) }\end{array}$ & $\begin{array}{c}\text { "Better WiFi" } \\
\text { "Space to have plug sockets } \\
\text { in lecture theatres to do } \\
\text { work on laptops." }\end{array}$ & 4 \\
\hline $\begin{array}{c}\text { General } \\
\text { (not specified) }\end{array}$ & $\begin{array}{l}\text { "Something seamless to } \\
\text { make students engaged, } \\
\text { and that is integrated into } \\
\text { the classroom." }\end{array}$ & 2 \\
\hline $\begin{array}{l}\text { Bringing the } \\
\text { outside world }\end{array}$ & $\begin{array}{l}\text { "Bringing experts or other } \\
\text { locations to the } \\
\text { classroom." }\end{array}$ & 1 \\
\hline $\begin{array}{c}\text { Futuristic mobile } \\
\text { devices }\end{array}$ & $\begin{array}{l}\text { "Just my mobile device } \\
\text { with seamless ways of } \\
\text { captures my thoughts, } \\
\text { content and arranging } \\
\text { them in a neat pattern } \\
\text { based on AI." }\end{array}$ & 1 \\
\hline
\end{tabular}

Table 1 - Thematic analysis of "blue skies thinking". 


\subsection{RQ 2 POTENTIAL BENEFITS AND CHALLENGES OF AR AND VR TECHNOLOGIES}

Participants' comments (in the discussion) regarding AR and VR technologies were mixed. On the one hand, participants saw potential advantages of "high-end" VR headsets (e.g., a powerful effect in experiencing different environments and high interactivity), "low-end" (Google Cardboard) VR apps (e.g., the cost is relatively low, availability of content, relatively simple content creation), as well as of Microsoft HoloLens (e.g., can create environments for safe practice - "a good way of letting future doctors fail in a more low-stress environment" and high interactivity) and mobile AR (e.g., it is relatively easy to use, affordable and can be useful in specific cases such as language learning). However, on the other hand, participants pointed out potential limitations such as: VR/ AR headsets (Oculus Rift and Microsoft HoloLens) can be used only with small groups of students due to still high cost per unit; dizziness and motion sickness issues (especially with the Oculus Rift and Google Cardboard headsets); complicated user interface, heavy to wear and hard to control virtual 3D objects (comments regarding Microsoft HoloLens); can be hard to manipulate the paper and phone at the same time (comments regarding mobile AR); low quality of some AR/VR apps and experiences; challenges with "bring your own device" (BYOD) model of integration (e.g., a requirement for students to have a suitable phone); hygiene issues (cleaning materials are necessary and keeping shared equipment clean can be challenging); lectures/students readiness to create AR/VR content; could be gimmicky and may not work for certain fields ("dependent very much on discipline").

\subsection{RQ 3 SIMPLIFIED DIDACTIC PROCESS MAPS}

Discussion with staff and students led to simplified didactic process maps creation on how specific aims could be achieved with given technologies and tools. We should stress that there was a large number of such maps created, but in this paper, we presented only simplified didactic process maps to reflect VR possibilities (Figure 1). For each there was a specific pedagogical goal and a series of steps to achieve that goal outlined.
4.3.1. FIGURE 1 - SIMPLIFIED DIDACTIC PROCESS MAP FOR VR

Take a VR field trip:

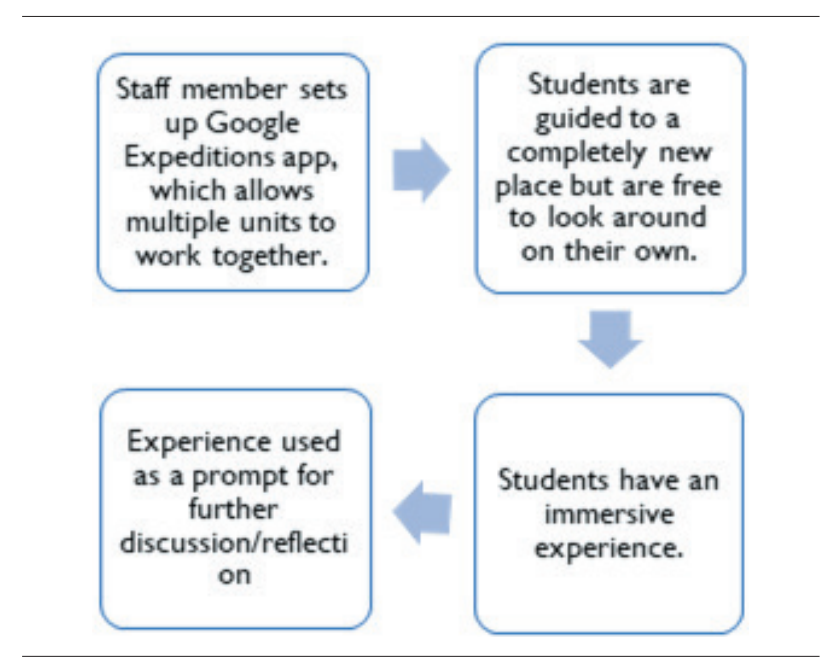

Very simple VR content creation via smartphone camera:

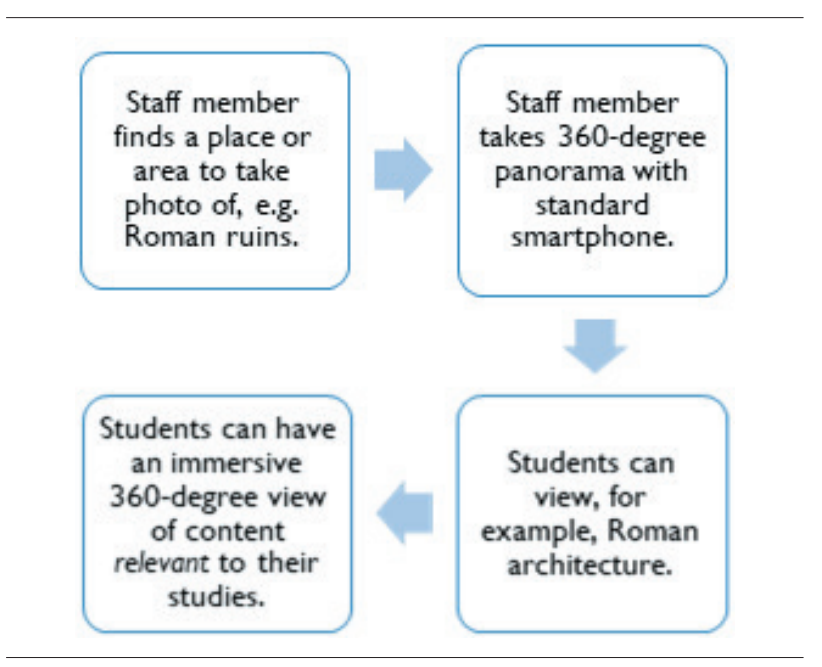

Creating a VR app:

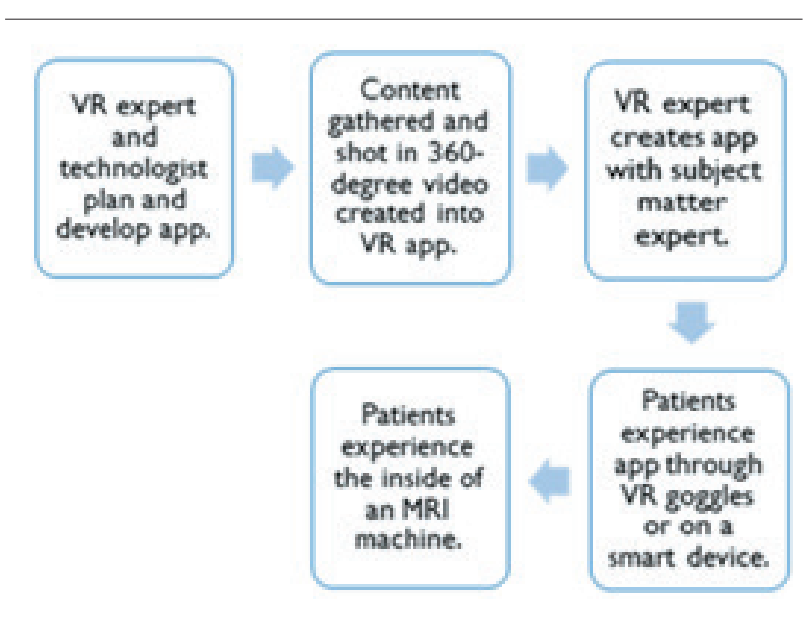




\section{DISCUSSION AND CONCLUSION}

There are several points to bear in mind in reviewing the data since students and staff members had a wide variety of views and needs; and there is no one perfect digital "solution" for improving students' engagement. The results of the other research questions (from this research) are presented in Detyna and Dommett [20].

The research question related to staff members and students' 'blue skies thinking' showed needed technological solutions in learning environments. The most prominent themes were regarding improving communication and collaboration in the lectures as well as improving visual presentation technology, lecture capture and physical infrastructure of the classrooms. Some of the indicated needs can be met with digital tools and technologies investigated in this research [20], but for some demands, technologies are not there yet.

In terms of the research question about benefits/ challenges of immersive technologies, VR can be used to create "high end" immersive experiences, but also aspects of "lower end" VR (e.g., $360^{\circ}$ environments) can be used to add a degree of interactivity and engagement to student communities both online and on campus [24].

Interactivity was mentioned by a number of participants as being of benefit, which chimes with the literature on the subject [25]. However, participants expressed skepticism that premade (off the shelf) AR/VR apps would work well in all disciplines. Also, one of the biggest problems with the use of immersive technologies in learning environments is that it is sometimes hard to transfer the interest of new technologies to the interest of the materials being studied [26].

The last research question was related to the simplified didactic process map creation. The simplified maps shown in this paper (regarding the use of VR) are a small subset of those created, and wider use was made in the institution. Additionally, as Zhou et al. [27] states, VR and AR use in education should be used to build on and help construct knowledge, based on existing understanding. We have built on the work of Radianti et al. [17] to give examples of implementation in practice. We should also be mindful of the resource implications, e.g., the last use case is dependent on significant time, resources and content creation outside of a lecture with a VR specialist. Reflecting back, having a diagrammatic representation was found to be of use by the academics involved in the study, and could potentially be of broader use.

\subsection{LIMITATIONS}

Limitations of the present study should be acknowledged. Firstly, the sample size $(\mathrm{N}=33)$ is reasonable but could have been increased to get greater depth of results. Secondly, we should be mindful that the landscape of digital AR/VR tools changes over time. For example, Google has announced that it is cancelling its Tour Creator authoring tool and the Expeditions app in 2021. Another (third) limitation to consider is the fact that the research did not study the long-term use of the tools.

\subsection{FINAL POINTS}

This research has shown that there are a number of promising avenues to help engage students in a learning environment, partially with digital tools. Still, the AR/VR technology should be an enabler rather than a means to an end, and sound pedagogy is the foundation of every good teaching approach (whether using digital technology or not).

We should also note that the current situation with the COVID-19 pandemic is likely to introduce significant changes in education and the wider world. The AR/ VR technology will likely gain in importance as a mechanism for students to experience field trips and fieldwork activities "virtually" if they are unable to visit in person [28]. Opportunities to combine face to face and online environments will also influence $\mathrm{HE}$ teaching.

\subsection{DECLARATION OF INTEREST STATEMENT}

The authors confirm there is no conflict of interest in relation to financial or non-financial interest in the area studied.

\section{REFERENCES}

[1] P. A. Kelly, P. Haidet, V. Schneider, N. Searle, C. L. Seidel, and B. F. Richards, "A comparison of in-class learner engagement across lecture, problem-based learning, and team learning using the STROBE classroom observation tool," Teach. Learn. Med., vol. 17, no. 2, pp. 112-118, Mar. 2005, doi: 10.1207/ s15328015tlm1702_4.

[2] H. G. Schmidt, S. L. Wagener, G. A. C. M. Smeets, L. M. Keemink, and H. T. van der Molen, "On the use and misuse of lectures in higher education," Heal. Prof. Educ., vol. 1, no. 1, pp. 12-18, Dec. 2015, doi: 10.1016/j.hpe.2015.11.010. 
[3] S. Mann and A. Robinson, "Boredom in the lecture theatre: An investigation into the contributors, moderators and outcomes of boredom amongst university students," Br. Educ. Res. J., vol. 35, no. 2, pp. 243258, Apr. 2009, doi: 10.1080/01411920802042911.

[4] J. T. DiPiro, "Why do we still lecture?," American Journal of Pharmaceutical Education, vol. 73, no. 8 . 2009, doi: 10.5688/aj7308137.

[5] E. J. Dommett, B. Gardner, and W. van Tilburg, "Staff and students perception of lecture capture," Internet High. Educ., vol. 46, Art. no. 100732, Jul. 2020, doi: 10.1016/j.iheduc.2020.100732.

[6] A. Saito and M. E. Smith, "Measurement and analysis of student (dis)engagement in higher education: A preliminary study," IAFOR J. Educ., vol. 5, no. 2, Sep. 2017, doi: 10.22492/ije.5.2.01.

[7] S. Freeman et al., "Active learning increases student performance in science, engineering, and mathematics," Proc. Natl. Acad. Sci., vol. 111, no. 23, pp. 8410-8415, 2014, doi: 10. 1073/pnas.1319030111.

[8] V. Trowler, "Student engagement literature review," The Higher Education Academy, York, UK, Commissioned report, Nov. 2010, Accessed: Apr. 15, 2020. [Online]. Available: https://www.heacademy.ac.uk/ system/files/studentengagementliteraturereview_1.pdf

[9] M. Detyna and M. Kadiri, "Virtual reality in the HE classroom: feasibility, and the potential to embed in the curriculum," J. Geogr. High. Educ., vol. 44, no. 3, pp. 474-485, 2020, doi: 10.1080/03098265.2019.1700486.

[10] M. Henderson, N. Selwyn, and R. Aston, "What works and why? Student perceptions of 'useful' digital technology in university teaching and learning," Stud. High. Educ., vol. 42, no. 8, pp. 1567-1579, 2017, doi: 10.1080/03075079.2015.1007946.

[11] J. W. M. Lai and M. Bower, "Evaluation of technology use in education: Findings from a critical analysis of systematic literature reviews," Journal of Computer Assisted Learning, vol. 36, no. 3, pp. 241-259, Jun. 2020, doi: 10.1111/jcal.12412.

[12] S. A. Licorish, H. E. Owen, B. Daniel, and J. L. George, "Students' perception of Kahoot!'s influence on teaching and learning," Res. Pract. Technol. Enhanc. Learn., vol. 13, no. 1, 2018, doi: 10.1186/s41039-0180078-8.

[13] I. Stojšić, A. Ivkov-Džigurski, O. Maričić, J. Stanisavljević, J. Milanković Jovanov, and T. Višnić, "Students' attitudes toward the application of mobile augmented reality in higher education," Drus. Istraz., vol. 29, no. 4, pp. 535-554, 2020, doi: 10.5559/di.29.4.02.

[14] M. Akçayır and G. Akçayır, "Advantages and challenges associated with augmented reality for education: A systematic review of the literature," Educ. Res. Rev., vol. 20, pp. 1-11, 2017, doi: 10.1016/j. edurev.2016.11.002.
[15] J. Garzón and J. Acevedo, "Meta-analysis of the impact of augmented reality on students' learning gains," Educational Research Review, vol. 27, pp. 244260, Jun. 2019, doi: 10.1016/j.edurev.2019.04.001.

[16] T. H. Laine, "Mobile educational augmented reality games: A systematic literature review and two case studies," Computers, vol. 7, no. 1, Mar. 2018, doi: 10.3390/computers7010019.

[17] J. Radianti, T. A. Majchrzak, J. Fromm, and I. Wohlgenannt, "A systematic review of immersive virtual reality applications for higher education: Design elements, lessons learned, and research agenda," Comput. Educ., vol. 147, Art. no. 103778, Apr. 2020, doi: 10.1016/j.compedu.2019.103778.

[18] A. Scavarelli, A. Arya, and R. J. Teather, "Virtual reality and augmented reality in social learning spaces: a literature review," Virtual Real., vol. 25, pp. 257-277, Mar. 2021, doi: 10.1007/s10055-02000444-8.

[19] E. Abad-Segura, M.-D. González-Zamar, J. C. InfanteMoro, and G. Ruipérez García, "Sustainable management of digital transformation in higher education: Global research trends," Sustainability, vol. 12, no. 5, Art. no. 2107, 2020, doi: 10.3390/su12052107.

[20] M. Detyna and E. J. Dommett, "An investigation into in-lecture digital tools for engagement: a feasibility study," Compass J. Learn. Teach., vol. 14, no. 1, 2021, doi: 10.21100/compass.v14i1.1114.

[21] P. E. Kahn, "Theorising student engagement in higher education," Br. Educ. Res. J., vol. 40, no. 6, pp. 1005-1018, Dec. 2014, doi: 10.1002/berj.3121.

[22] V. Braun and V. Clarke, "Using thematic analysis in psychology," Qual. Res. Psychol., vol. 3, no. 2, pp. 77-101, 2006, doi: 10.1191/1478088706qp063oa.

[23] B. Döbeli Honegger and M. Notari, "Visualizing learning processes using didactic process maps," in Investigations of E-Learning Patterns: Context Factors, Problems and Solutions, C. Kohls and J. Wedekind, Eds., Hershey, PA, USA: IGI Global, 2010, pp. 135-148.

[24] A. Atkins, F. Charles, and N. Adjanin, "A new realm for distance and online learning: 360-degree VR," Teaching Journalism \& Mass Communication, vol. 10, no. 2, pp. 51-54, 2020.

[25] J. Begum, S. I. Ali, and M. Panda, "Introduction of interactive teaching for undergraduate students in community medicine," Indian J. Community Med., vol. 45, no. 1, pp. 72-76, 2020, doi: $10.4103 / \mathrm{ijcm}$. IJCM_232_19.

[26] L. Daniela, "Smart pedagogy for technologyenhanced learning," in Didactics of Smart Pedagogy: Smart Pedagogy for Technology Enhanced Learning, L. Daniela, Ed., Cham, Switzerland: Springer, 2019, pp. 3-21, doi: 10.1007/978-3-030-01551-0_1. 
[27] Y. Zhou, S. Ji, T. Xu, and Z. Wang, "Promoting knowledge construction: A model for using virtual reality interaction to enhance learning," Procedia Computer Science, vol. 130, pp. 239-246, 2018, doi: 10.1016/j.procs.2018.04.035.

[28] Sershen, I. Stojšić, and S. Munien, "Teaching practicals in the time of physical distancing: Advances, challenges and recommendations for higher education.," in Technology-Based Teaching and Learning in Higher Education During the Time of COVID-19, N. Ndimande-Hlongwa, L. Ramrathan, N. Mkhize, and J. A. Smit, Eds., Durban, South Africa: CSSALL Publishers, 2020, pp. 34-53, doi: 10.29086/978-09869936-1-9/2020/AASBS02 